\title{
Analysis and Design of a Parallel CUK Power Factor Correction Circuit Based on Power Balance Control Technique
}

\author{
Uthen Kamnarn Non-member (King Mongkut's Institute of Technology North Bangkok, k_uthen@ hotmail.com) \\ Viboon Chunkag Non-member (King Mongkut’s Institute of Technology North Bangkok, vck@kmitnb.ac.th)
}

Keywords: parallel single-phase CUK, power factor correction, power balance control technique

The analysis and design of a parallel AC to DC CUK converter circuit based on power balance control technique for DC Distributed Power System (DPS) applications are presented. The three parallel modules system with fast dynamic response using single voltage loop control and inductor current calculator for input current wave shaping, inductor current sharing and output voltage regulation, while keeping the power factor very close to unity have been shown. The experimental prototype have been built with a DC output voltage $-48 \mathrm{~V}$ and output power $750 \mathrm{~W}$. Fig. 1 shows the waveform of input voltage and current. Evidently, the line current is almost in phase with the input phase voltage and nearly sinusoidal. The input current total harmonic distortion (THD) is $3 \%$ at full load and $6 \%$ at half load. Figure 2 shows three individual inductor currents at step load change from $100 \%$ to $50 \%$. Due to the effect of difference inductance values and parasitic in input inductors, these inductor currents are not exactly equal. Fig 3 shows inverted transient response of output voltage and load current with the ripple output voltage $3.2 \mathrm{~V}$. It is indicated that the good dynamic performance can be achieved.

The CUK PFC parallel scheme can provide good power factor from $200 \mathrm{~W}$ to full load. Both the power factor and $\mathrm{THD}_{i}$ are insensitive to the line voltage. Therefore, CUK converters in CCM operation are suitable as power-factor-correction over a variation of input voltage. Experimental prototype with a total of $750 \mathrm{~W}$ output power

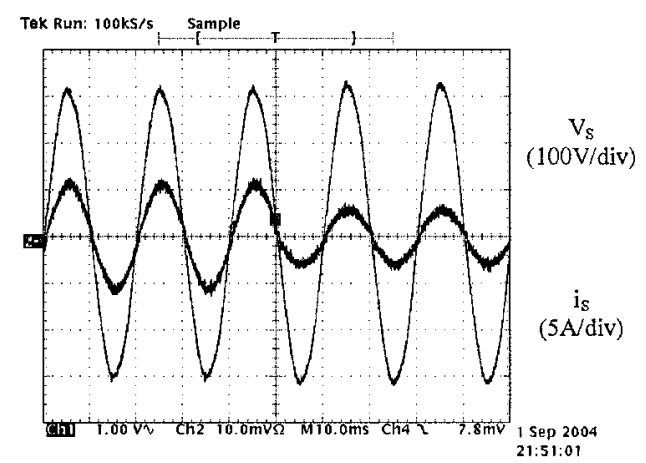

Fig. 1. Transient response of input voltage and current of the proposed system

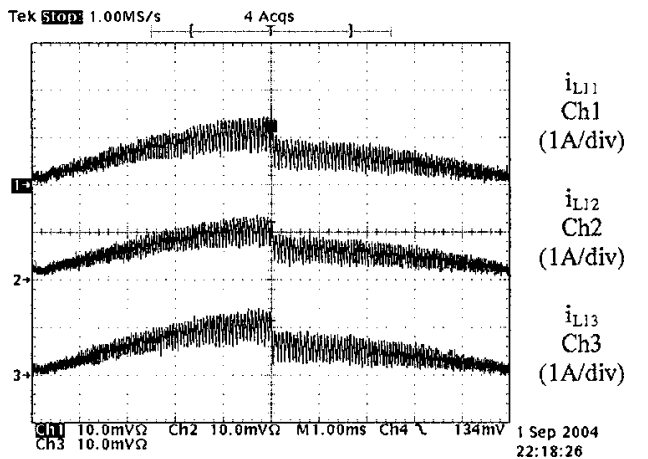

Fig. 2. Transient response of inductor current for three modules

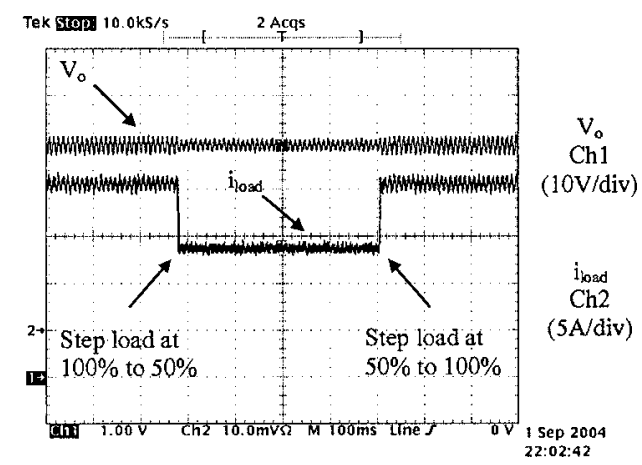

Fig. 3. Experimental transient response for step load variation from $100 \%$ to $50 \%$ and back to $100 \%$

for three power modules and common output $-48 \mathrm{~V} @-15.625 \mathrm{~A}$ is built toverify the concept presented. It has been shown that good output voltage regulation, input power factor correction and the inductor current sharing are achieved by controlling the duty-ratio for all modules. The proposed approach offers the following advantages: simple control and fast dynamic response. A high power factor $(\mathrm{PF}>0.99)$ can still be achieved. A $750 \mathrm{~W}$ prototype modular converter system with $85 \%$ efficiency operating completely in the CCM has confirmed the analysis. 


\title{
Analysis and Design of a Parallel CUK Power Factor Correction Circuit Based on Power Balance Control Technique
}

\author{
Uthen Kamnarn* ${ }^{*}$ Non-member \\ Viboon Chunkag* Non-member
}

The analysis and design of a parallel AC to DC CUK converter circuit based on power balance control technique for DC Distributed Power System (DPS) applications are presented. The three parallel modules system with fast dynamic response using single voltage loop control and inductor current calculator for input current wave shaping, inductor current sharing and output voltage regulation, while keeping the power factor very close to unity have been shown. The experimental prototype have been built with a DC output voltage $-48 \mathrm{~V}$ and output power $750 \mathrm{~W}$. Each converter operates in Continuous Conducting Mode (CCM) together with hysteresis current control. The experimental results indicate that such scheme is effective and offers the fast transient response. The results obtained are: power factor greater than 0.99 and input current Total Harmonic Distortion (THD) less than 3\%. The system offers $85 \%$ efficiency and provide good current sharing among the converter modules.

Keywords: parallel single-phase CUK, power factor correction, power balance control technique

\section{Introduction}

In general, conventional off-line switching power supplies draw non-sinusoidal input current waveform, resulting in high input current harmonics, low input power factor, high losses on power lines and causing malfunction of electrical equipment. Recently, AC to DC converters with unity input power factor have been proposed to overcome the above shortcomings. The main fuction of these converters is to shape the input line current to be in phase and sinusoidal as the input voltage. Therefore, the input power factor can be improved to nearly unity and the input current harmonics can be eliminated. Various circuit configurations and control schemes have been proposed ${ }^{(1)-(3)}$ and used in practical. Active Power Factor Correction (PFC) technique, using a DC to DC converter, has been successfully implemented to improve the power factor and reduce input current distortion in single-phase line current rectification ${ }^{(4)}$.

Generally, a single high-power power supply has some disadvantages, such as heat dissipation and expensive components of high power ratings. Besides, it would take much time and effort to have a variety of designs for different power levels. Distributed power system has been developed for using in electronic and telecommunication systems. There are two distributed power approaches: AC bus and DC bus ${ }^{(5)(6)}$. The DC approach employs an intermediate DC voltage; $48 \mathrm{~V}$, which is distributed to multiple DC to DC converters in the system. The complexity of the front end DC DPS can be overcome using modular single-phase AC to DC PFC scheme as shown in Fig. 1. A number of parallel-connected singlephase power factor correction circuits have been developed recently ${ }^{(7)(8)}$. Boost and CUK converter are used in PFC

\footnotetext{
* King Mongkut's Institute of Technology North Bangkok

1518 Piboonsongkram Rd, Bangkok 10800, THAILAND
}

applications ${ }^{(9)(10)}$. In addition, the main advantages of the CUK topology are: possibility of isolation, output voltage step up or step down and magnetic coupling. The main disadvantage in two-stage scheme employing a PFC boost and DC to DC converter is the high cost and low efficiency. Moreover, single-stage method using the simplest flyback converter is not able to tightly regulate the output voltage ${ }^{(11)}$.

In this paper, the design and implementation of a DC bus parallel-connected PFC approach is proposed to overcome the disadvantages of the three conversion stages in cascade (PFC stage, DC to AC and AC to DC). The objective of the proposed parallel PFC scheme is to reduce the number of stages and improves dynamic response. The experimental results demonstrate that the proposed system works well, fast dynamic response, simple control strategy, good power factor correction and the inductor current sharing. There are achieved by controlling the duty-ratio for all converter modules.

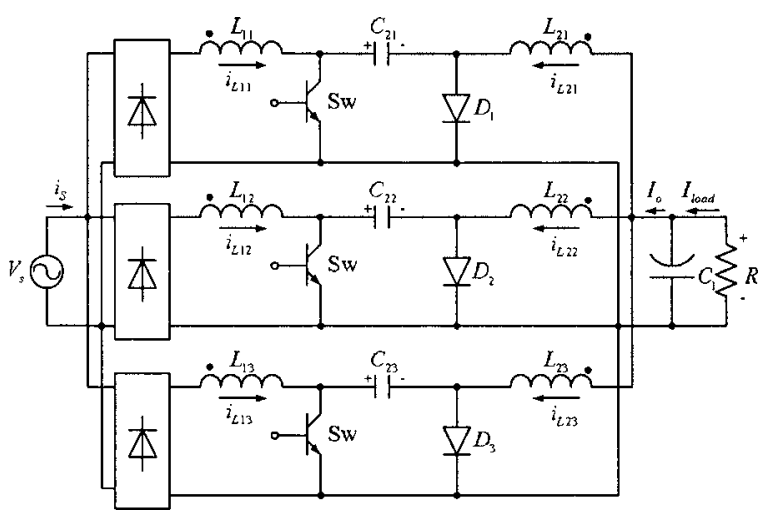

Fig. 1. Modular single-phase AC to DC CUK PFC scheme 


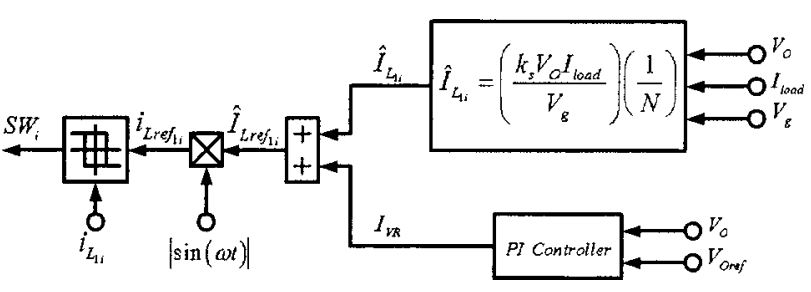

Fig. 2. Block diagram for the proposed control strategy

\section{Proposed Topology and Control Strategy}

2.1 The Power Stage The CUK converter presents a current source characteristics, which is suitable for high power factor applications. The schematic diagram of three DC to DC non-isolated converters is shown in Fig. 1. All power devices of the PFC circuit, including the bridge rectifier, and the power circuit components of the CUK converter, are modularized. A single capacitor output, $C_{1}$, is connected at the output terminals for filtering the power frequency output voltage ripples.

2.2 The Control Stage The power balance control technique for the proposed system is shown in Fig. 2. It shows a simple control block diagram, which can be easily implemented by analog circuits. It consists of a sinusoidal reference, proportional-plus-integral controller and inductor current calculator. The inductor current calculator computes the desired AC input current. The output voltage is measured and compared to the reference voltage. The voltage error is injected into an appropriate voltage controller. The summation signal is multiplied by a signal of rectified input voltage and compared to a signal of the input inductor current. The resulting modulation signal is processed by a suitable hysteresis current control, generating the driving signal to control the switch.

\section{Average Small Signal Analysis}

The averaged small signal model of the parallel CUK PFC circuits is based on a power balance control. There are two major concerns of the small signal performance of the circuit. Firstly, the control circuit has to force the input line current to track the input voltage waveform. The second consideration is that, the analysis of the circuit is based on a cycle-to-cycle basis. In this case, the small-signal analysis is performed on an average basis over a complete half-cycle of the sinusoidal input, assuming that the input current is properly controlled to track the scaled input voltage. And also the AC source and all components in the system are ideal.

3.1 Parallel Connection of Modular Power Circuit Using Three Single-Phase CUK Converters The power balance equation for half-cycle of the input sinewave voltage is:

$$
V_{g} \cdot \sum_{i=1}^{N} I_{L_{1 i}}=V_{o} I_{o}
$$

$V_{g}$ is the rms value of rectifier voltage,

$I_{L_{1 i}}$ is the rms values of input inductor current,

$V_{o}$ is the DC output voltage,

$I_{o}$ is the average output current over a half-cycle,

$N$ is number of converter in the system.

$$
\hat{I}_{\text {Lrefii }}=\hat{I}_{L_{1 i}}+I_{V R}
$$

$\hat{I}_{L_{1 i}}$ is peak current from inductor current calculator.

$I_{V R}$ is correcting signal from PI controller. The desired output voltage can be achieved by the inductor current calculator and the voltage regulator. The inductor current calculator computes the desired inductor current in each module according to the load current, the DC output voltage and the rms input voltage. Since the basic concept of the power balance control is that the input power and the output power of the system are equal for half-cycle of the input sinewave voltage, the computed peak value of the inductor current is:

$$
V_{g} \cdot \sum_{i=1}^{N} \hat{I}_{L_{1 i}}=k_{s} V_{o} I_{\text {load }}
$$

let $\hat{I}_{L_{11}}=\hat{I}_{L_{12}}=\hat{I}_{L_{13}}$

$$
\hat{I}_{L_{1 i}}=\frac{k_{s} V_{o} I_{\text {load }}}{N V_{g}}
$$

The inductor reference current is:

$$
i_{\text {Lref }_{1 i}}=\hat{I}_{\text {Lref }_{1 i}}|\sin (\omega t)|
$$

The dynamic equation of the output voltage is:

$$
\sum_{i=1}^{N} I_{L_{2 i}}=I_{o}=C_{1} \frac{d V_{o}}{d t}+I_{\text {load }} \ldots \ldots \ldots \ldots \ldots \ldots
$$

$I_{\text {load }}$ is the load current of the proposed system.

For derivation of the small signal model, let:

$$
\begin{aligned}
& V_{g}=\bar{V}_{g}+\tilde{v}_{g} \ldots \ldots \ldots \\
& I_{L_{1 i}}=\bar{I}_{L_{1 i}}+\tilde{i}_{L_{1 i}} \ldots \ldots \\
& V_{o}=\bar{V}_{o}+\tilde{v}_{o} \ldots \ldots \ldots \\
& I_{o}=\bar{I}_{o}+\tilde{i}_{o} \ldots \ldots \ldots \\
& \hat{I}_{\text {Lref }} \ldots \ldots \\
& I_{V R}=\overline{\hat{I}}_{\text {Lref }}+\bar{I}_{V R}+\overline{\hat{i}}_{\text {Lref }} \ldots \ldots \\
& \hat{i}_{\text {VR }} \ldots \ldots \\
& \hat{I}_{L_{1 i}}=\overline{\hat{I}}_{L_{1 i}}+\tilde{\hat{i}}_{L_{1 i}} \ldots \ldots \\
& I_{\text {load }}=\bar{I}_{\text {load }}+\tilde{i}_{\text {load }} \ldots \ldots
\end{aligned}
$$

where the $\bar{V}$ means steady-state value and $\tilde{v}$ means the introduced perturbation (small-signal value). Applying the perturbations in Eq. 1, Eq. 2, Eq. 4, and Eq. 6, and performing the small-signal approximation $(\tilde{v} . \tilde{v}=0)$ results in:

$$
\begin{aligned}
& \tilde{i}_{o}=\frac{k_{r m s} N \overline{\hat{I}}_{\text {Lref }}}{\bar{V}_{o}} \tilde{v}_{g}+\frac{k_{r m s} N \bar{V}_{g}}{\bar{V}_{o}} \tilde{\hat{i}}_{\text {Lref }}-\frac{\bar{I}_{o}}{\bar{V}_{o}} \tilde{v}_{o} \ldots \ldots \\
& \tilde{i}_{o}=C_{1} \frac{d \tilde{v}_{o}}{d t}+\tilde{i}_{\text {load }} \\
& \tilde{i}_{\text {Lrefii }}=\tilde{\hat{i}}_{L_{1 i}}+\tilde{i}_{V R} \\
& \tilde{\hat{i}}_{L_{1 i}}=\frac{k_{s} \bar{V}_{o}}{N \bar{V}_{g}} \tilde{i}_{\text {load }}+\frac{k_{s} \bar{I}_{\text {load }}}{N \bar{V}_{g}} \tilde{v}_{o}-\frac{k_{s} \bar{V}_{o} \bar{I}_{\text {load }}}{N\left(\bar{V}_{g}\right)^{2}} \tilde{v}_{g}
\end{aligned}
$$




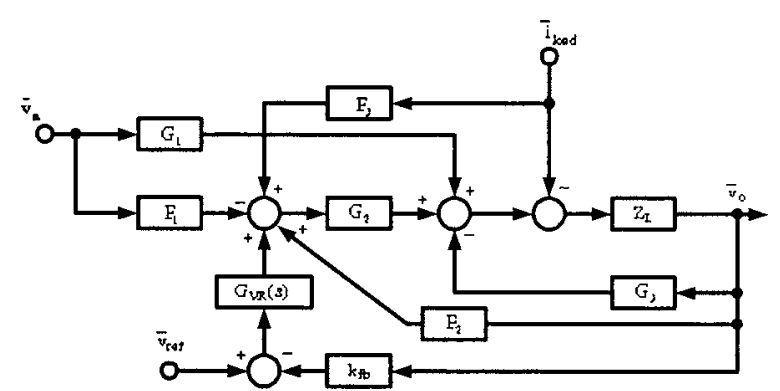

Fig. 3. Small-signal circuit diagram of proposed system

According to Eq. 15 to Eq. 18 and combining with the voltage regulator $G_{V R}(s)$, Fig. 3 shows the small signal control block diagrams of the proposed system, the parameters are given by:

$$
\begin{aligned}
& G_{1}=\frac{k_{r m s} N \overline{\hat{I}}_{\text {Lref }_{1 i}}}{\bar{V}_{o}} \ldots \\
& G_{2}=\frac{k_{r m s} N \bar{V}_{g}}{\bar{V}_{o}} \ldots . \\
& G_{3}=\frac{\bar{I}_{o}}{\bar{V}_{o}} \ldots \ldots \ldots \\
& F_{1}=\frac{k_{s} \bar{V}_{o} \bar{I}_{\text {load }}}{N\left(\bar{V}_{g}\right)^{2}} \cdots \cdot \\
& F_{2}=\frac{k_{s} \bar{I}_{\text {load }}}{N \bar{V}_{g}} \ldots \ldots \\
& F_{3}=\frac{k_{s} \bar{V}_{o}}{N \bar{V}_{g}} \ldots \ldots . \\
& Z_{L}(s)=\frac{1}{C_{1} S} \cdots \cdots
\end{aligned}
$$

Therefore, the output voltage can be expressed as

$$
\tilde{v}_{o}=T_{1} \tilde{v}_{r e f}+T_{2} \tilde{v}_{g}-Z_{o} \tilde{i}_{\text {load }}
$$

Applying Mason gain formula to the block diagram as shown in Fig. 3 we obtain transfer functions are given by

$T_{1}$ is the control function,

$T_{2}$ is the audio susceptibility,

$Z_{o}$ is the output impedance.

where

The control function: $T_{1}$

$$
\frac{\tilde{v}_{o}}{\tilde{v}_{r e f}}=\frac{G_{V R} G_{2} Z_{L}}{1+Z_{L} G_{V R} G_{2} k_{f b}+Z_{L} G_{3}-Z_{L} G_{2} F_{2}} \cdots \cdots
$$

The audio susceptibility: $T_{2}$

$$
\frac{\tilde{v}_{o}}{\tilde{v}_{g}}=\frac{Z_{L} G_{V R}-Z_{L} F_{1} G_{2}}{1+Z_{L} G_{V R} G_{2} k_{f b}-Z_{L} F_{2} G_{2}+Z_{L} G_{3}}
$$

The output impedance: $Z_{o}$

$$
\frac{\tilde{v}_{o}}{\tilde{i}_{\text {load }}}=\frac{Z_{L}-G_{2} F_{3} Z_{L}}{1+Z_{L} G_{V R} k_{f b} G_{2}+Z_{L} G_{3}-Z_{L} G_{2} F_{2}}
$$

The output impedance and the audio susceptibility are zero, $\frac{\tilde{v}_{o}}{\tilde{v}_{g}}=\frac{\tilde{v}_{o}}{\tilde{i}_{\text {load }}}=0$

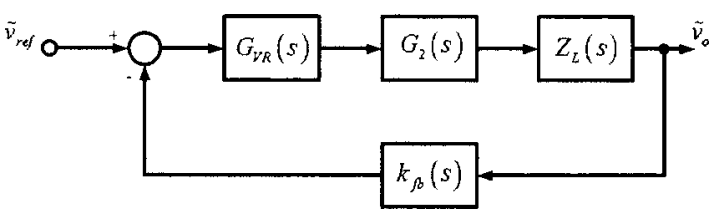

Fig. 4. Block diagram of the voltage loop

Therefore, the gain $k_{S}$ can be expressed as:

$$
\begin{aligned}
& G_{1}=G_{2} * F_{1} \ldots \\
& k_{s}=k_{r m s}^{-1}=\sqrt{2} .
\end{aligned}
$$

Then, the output voltage can be expressed as:

$$
\tilde{v}_{o}=\frac{N G_{V R} \bar{V}_{g} k_{r m s}}{\bar{V}_{o} C_{1} S+N G_{V R} \bar{V}_{g} k_{r m s} k_{f b}} \tilde{v}_{r e f} \ldots \ldots \ldots \ldots
$$

$k_{r m s}$ is RMS gain.

$k_{f b}$ is feedback gain.

3.2 Analysis of Loop Gain According to Eq. 32, Fig. 4 shows the block diagram of the voltage regulation loop. In practice, it is convenient to use the loop gain for analyzing the stability of the closed-loop system. Considering this fact, the Nyquist criterion can be translated as the crossover of the loop gain. The open-loop phase shift at the crossover frequency must lag by less than $180^{\circ}$. If the lag is $180^{\circ}$, negative feedback provides a shift of another $180^{\circ}$, resulting in a total of $360^{\circ}$ (or zero). A gain of magnitude one and phase of $360^{\circ}$ around the loop make the loop unstable. A phase margin of at least $45^{\circ}$ is commonly used criterion for stability. Compensator transfer function $G_{V R}(s)$ is designed to avoid unstable operation when the source voltage or load are subjected to large variations. These variations change the operation conditions of the converter circuits, affecting their dynamic characteristics.

\section{Controller Design}

Feedback compensation is required to regulate the output voltage over the full input voltage and output load variation. An integral-and-lead network provides the optimum compensation for resistive loads. Two parameters must be selected for compensation network: the location of the zero, and the high-frequency gain. Since the main function of the switching mode rectifier is to keep the input current to be sinusoidal and in phase with the input line voltage. Therefore, bandwidth of the voltage regulation loop should be smaller than the line frequency. A suitable crossover frequency is $1 / 6$ the frequency of input line ${ }^{(12)}$.

Here, a PI controller is:

$$
G_{V R}(s)=\frac{k_{p}\left(S+\omega_{z}\right)}{S}
$$

when

$G_{V R}(s)$ is transfer function of PI controller.

$k_{p}$ is the gain of PI controller.

$\omega_{z}$ is the location of the zero.

Plant transfer function is:

$$
P T F=\frac{N \bar{V}_{g} k_{r m s} k_{f b}}{\left(\bar{V}_{o} C_{1}\right) S}
$$




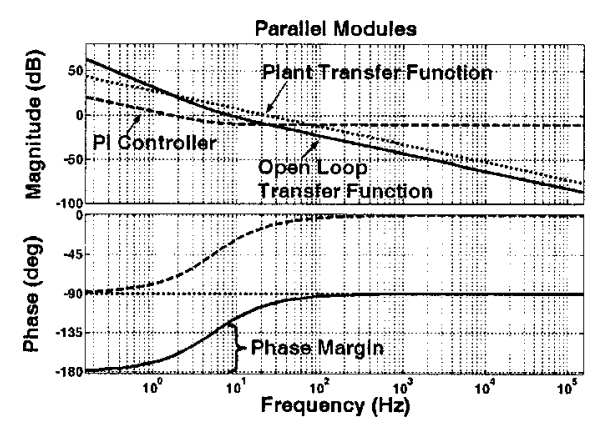

Fig. 5. Bode plot of the proposed system

Table 1. Characteristics of the CUK converters

\begin{tabular}{c|c}
\hline Characteristic & Parallel Modules \\
\hline Input Voltage & $220 V_{r m s}$ \\
\hline Line Frequency & $50 \mathrm{~Hz}$ \\
\hline Rated Module & $375 \mathrm{~W} /$ cell \\
\hline Total Output Power & $750 \mathrm{~W}$ \\
\hline Output Voltage & $-48 \mathrm{~V}$ \\
\hline$L_{11}, R_{11}$ & $3.1541 \mathrm{mH}, 1.1040 \Omega$ \\
\hline$L_{21}, R_{21}$ & $1.0764 \mathrm{mH}, 0.3190 \Omega$ \\
\hline$L_{12}, R_{12}$ & $3.1873 \mathrm{mH}, 0.8160 \Omega$ \\
\hline$L_{22}, R_{22}$ & $1.0360 \mathrm{mH}, 0.3388 \Omega$ \\
\hline$L_{13}, R_{13}$ & $3.1617 \mathrm{mH}, 0.7769 \Omega$ \\
\hline$L_{23}, R_{23}$ & $1.0880 \mathrm{mH}, 0.3260 \Omega$ \\
\hline$C_{21}, C_{22}, C_{23}$ & $1 \mu F$ \\
\hline$C_{1}$ & $13,600 \mu F$ \\
\hline$k_{p}, \omega_{Z}$ & $0.3,33$ \\
\hline
\end{tabular}

Open loop transfer function is:

$$
O L T F=\left(G_{V R}(s)\right)\left(\frac{N \bar{V}_{g} k_{r m s} k_{f b}}{\left(\bar{V}_{o} C_{1}\right) S}\right)
$$

The Bode diagram of Eq.33, Eq.34, and Eq. 35, are presented in Fig. 5. Since this is a linear system, superposition technique can be applied to derive the overall system transfer function. By superimposing the gains and phases of the stage around the loop, a Bode plot of the overall system is generated. The high-frequency gain and zero of the compensation network can then be placed to optimize the system performance. Fig. 5 combines the Bode plots of the stages and $180^{\circ}$ phase shift is also added to account for the negative feedback of the system. The outer voltage loop is designed to have a crossover frequency of $8 \mathrm{~Hz}$. It also gives a $56^{\circ}$ phase margin at crossover frequency. Table 1 shows the design results of a $750 \mathrm{~W},-48 \mathrm{~V}$, parallel three modules AC to DC CUK converters.

\section{Simulation Results}

The simulation results of a $750 \mathrm{~W},-48 \mathrm{~V}$ parallel $\mathrm{AC}$ to DC CUK converters are shown through Fig. 6 to Fig. 10. A simple PI controller is used for the outer voltage control loop. The inductor current calculator feeds the current references of the three single-phase PFC modules forcing current sharing between them. The effectiveness of the power balance control technique is examined by computer simulation. Using the specification shown in the table 1 , the configuration of parallel modules AC to DC CUK converter is simulated using SIMULINK program. The proposed of this simulation is to verify the control algorithms, design the controller parameters, and study the static and dynamic performances of the system before building the prototype.

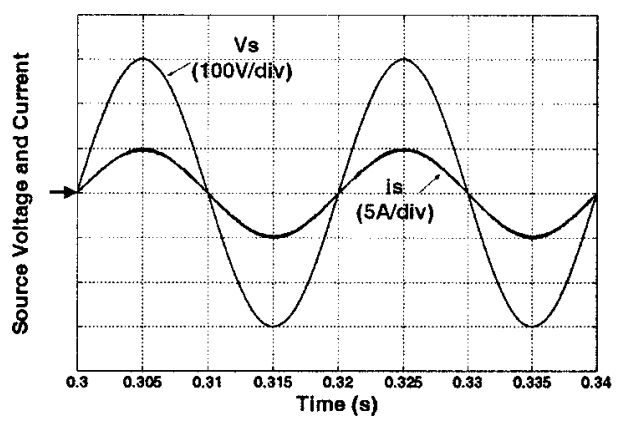

Fig. 6. Simulation result of input voltage and current waveforms of the proposed system

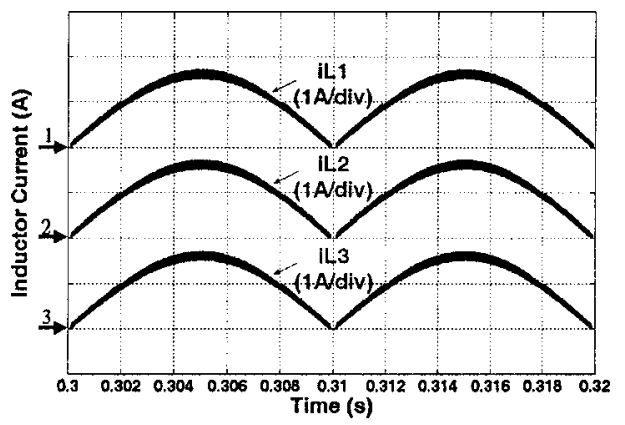

Fig. 7. Simulation result of inductor current waveforms of proposed system

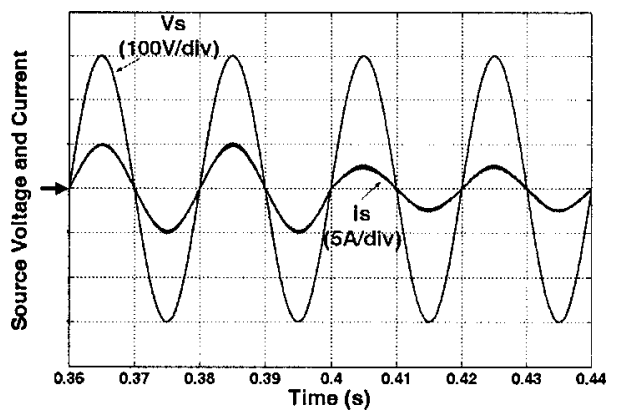

Fig. 8. Simulated transient response of input voltage and current

5.1 Steady State Response Condition Simulated input current and voltage waveforms, individual inductor current waveforms of Fig. 1 when $\mathrm{N}=3$ are shown in Fig. 6 and Fig. 7. The simulated input voltage and current at the full load $(750 \mathrm{~W})$ are shown in Fig. 6. Evidently, the line current is exactly in phase with the input line voltage and nearly sinusoidal. Thus, the input power factor approaches unity. The simulated of three individual inductor currents at full load are shown in Fig. 7. The results show that converter can share inductor current in each converter equally, while keeping the power factor very close to unity.

5.2 Transient Response Condition Simulation results of Fig. 1 when $\mathrm{N}=3$ and output power step change from $750 \mathrm{~W}$ to $375 \mathrm{~W}$ and vice versa are shown in Fig. 8 to Fig. 10. The simulation result of transient response of the input voltage and current at load change from $750 \mathrm{~W}$ to $375 \mathrm{~W}$ are shown in Fig. 8. The simulated transient response of three individual inductor currents while load had been changed from $750 \mathrm{~W}$ to $375 \mathrm{~W}$ are shown in Fig. 9. The simulated transient response of the output voltage and step load current from 


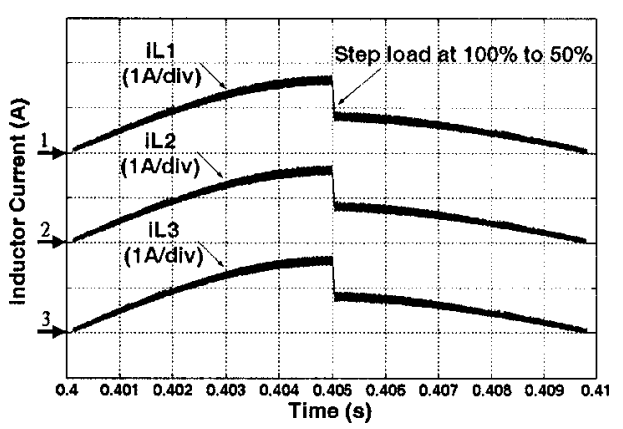

Fig. 9. Simulated transient response of inductor current
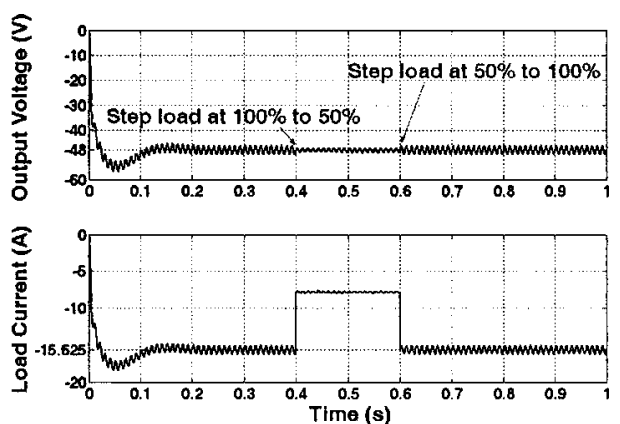

Fig. 10. Simulated transient response of output voltage and load current

$750 \mathrm{~W}$ to $375 \mathrm{~W}$ and back to $750 \mathrm{~W}$ are shown in Fig. 10. The characteristics of the power factor and dynamic response of the proposed system has high input power factor and fast dynamic response.

\section{Experimental Results}

The proposed distributed power system is shown in Fig. 11. The system consists of three power modules $375 \mathrm{~W}$ AC to DC PFC stage, which employs a regular CUK PFC converter. The modules are connected in parallel. The controller performs three main functions: to control inductor current sharing, to regulate output voltage and to shape input current to envelope defined by the input voltage. The result leads to high power factor and low harmonic currents. The analog circuit is used in the control circuitry of the prototype. Experimental results are shown in Fig. 12 to Fig. 24.

6.1 Steady State Response Condition In the following, experimental results taken from parallel CUK PFC circuit is reported, with continuous current mode control. Steady state response of Fig. 11 when $\mathrm{N}=3$ are shown in Fig. 12 to Fig. 15. The waveform of input voltage and current at full load are shown in Fig. 12. Evidently, the line current is almost in phase with the input line voltage and nearly sinusoidal. Thus, the input power factor approaches unity. The current THD was 3\%, which was taken from a Digital power meter YOKOGAWA model 2531 A. Three individual inductor currents at full load are shown in Fig. 13. Because of the effect of difference inductance values and parasitic in input inductors, these inductor currents are not exactly equal. However, all individual inductor currents are approximately same amplitude. This means that the proposed control strategy can share inductor current in each converter, while keeping the power factor very close to unity. Fig. 14 shows inverted steady state response of output voltage at

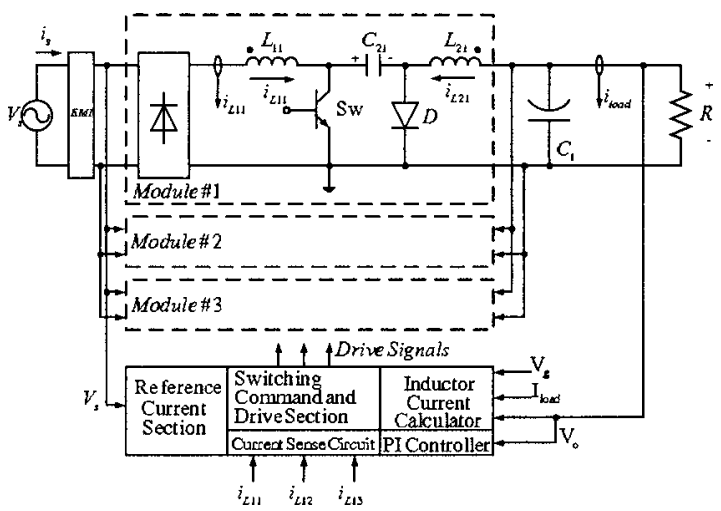

Fig. 11. System configuration block diagram of DPS with power balance control technique

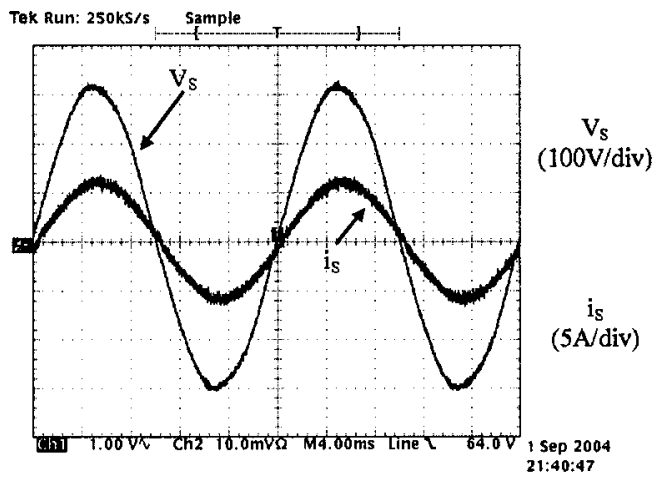

Fig. 12. Input voltage and current waveforms of the proposed system

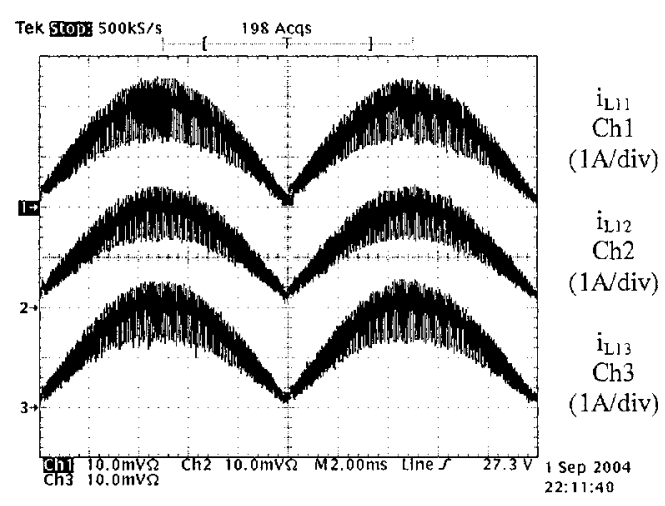

Fig. 13. Inductor current waveforms of the proposed system

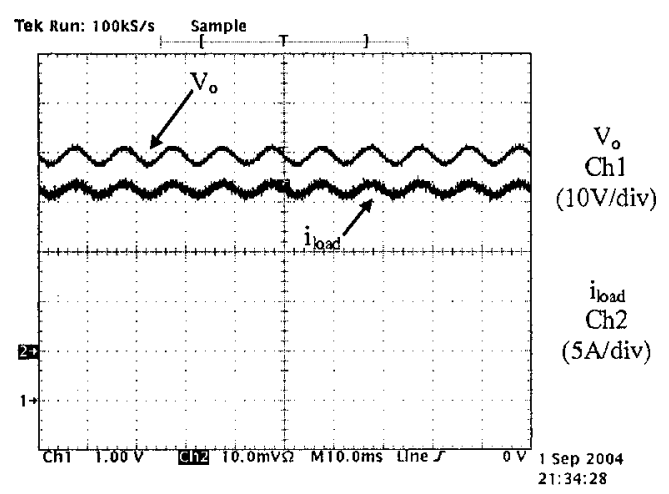

Fig. 14. Inverted output voltage and load current of the proposed system 


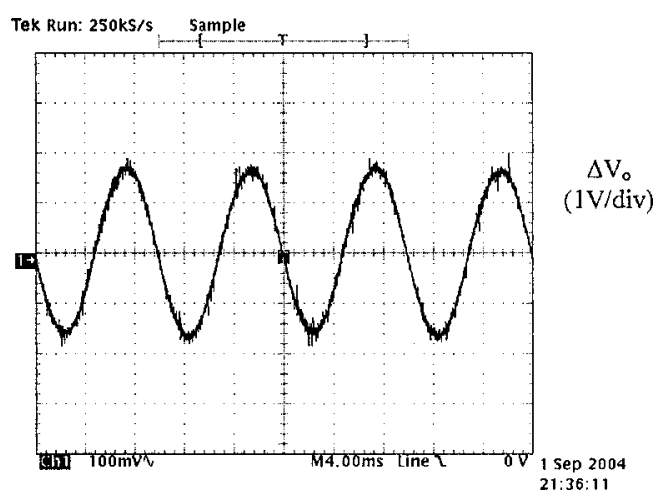

Fig. 15. Waveform of the ripple output voltage

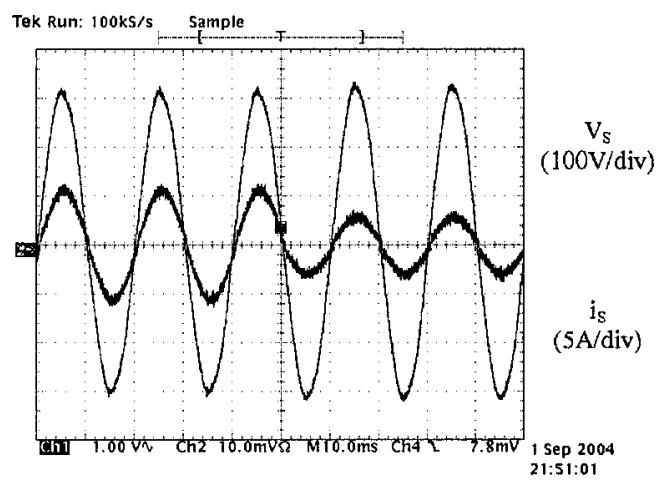

Fig. 16. Transient response of input voltage and current of the proposed system

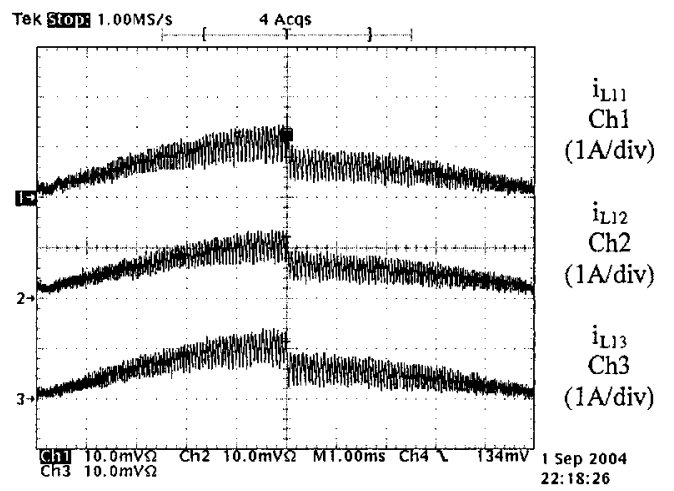

Fig. 17. Transient response of inductor current for three modules

$-48 \mathrm{~V}$ and load current at $-15.625 \mathrm{~A}$ and Fig. 15 shows the ripple output voltage $\Delta V_{o}=3.2 \mathrm{~V}(6.66 \%)$ when output capacitor is $13,600 \mu F$.

6.2 Transient Response Condition The dynamic response was tested by a load step change from $100 \%$ to $50 \%$ and back to $100 \%$ load. The results are shown in Fig. 16 to Fig. 20. The experimental results of transient response of the input voltage and current at load change from $100 \%$ to $50 \%$ are shown in Fig. 16. The closed up of three individual inductor currents while load had been changed from $100 \%$ to $50 \%$ are shown in Fig. 17. The experimental results in Fig. 16 to Fig. 17 indicate that such scheme is effective and parallel AC to DC converter has fast transient response characteristic. The current THD is $6 \%$ at a half load.

The results show in Fig. 18 to Fig. 20 were taken by the inverted probe of oscilloscope. Fig. 18 shows the experimental

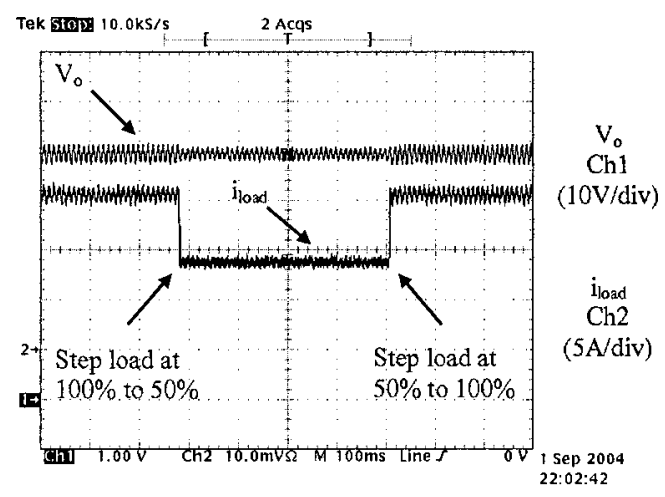

Fig. 18. Experimental transient response for step load variation from $100 \%$ to $50 \%$ and back to $100 \%$

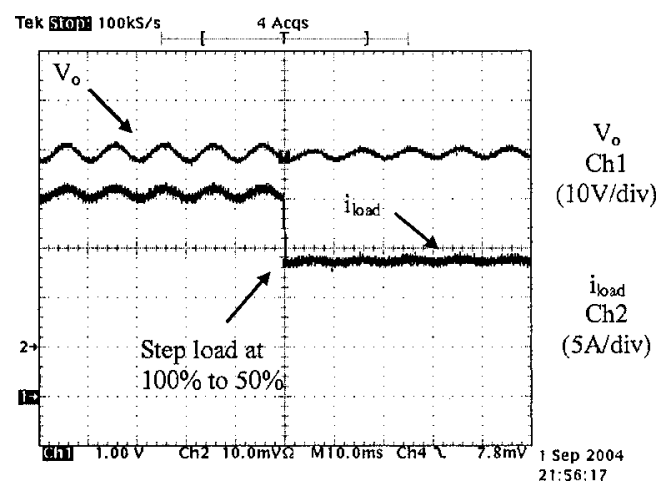

Fig. 19. Closed up of transient response of output voltage and load current at $750 \mathrm{~W}$ to $375 \mathrm{~W}$

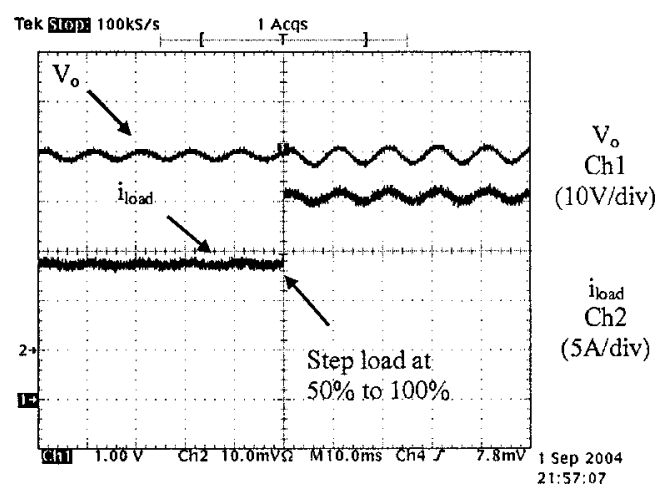

Fig. 20. Closed up of transient response of output voltage and load current at $375 \mathrm{~W}$ to $750 \mathrm{~W}$

results of the parallel AC to DC CUK converters under step load change from $750 \mathrm{~W}$ to $375 \mathrm{~W}$ and back to $750 \mathrm{~W}$, fast dynamic transient response has been achieved. It can be observed from Fig. 19 and Fig. 20 that the output voltage recovered to its steady state within 1 cycle and input current can still maintain a high-quality sinusoidal waveform. It is indicated that the good dynamic performance can be achieved.

6.3 The Performance of the Proposed System In this section, the performance experimental results of parallel CUK power-factor-correction circuits are reported, in terms of inductor current in each module, power factor, efficiency, total harmonics distortion of the line current $\left(\mathrm{THD}_{i}\right)$ and standard IEC 61000-3-2 class A limits. It was designed that the converters to operate in continuous conduction mode and measured with the Digital power meter model $2531 \mathrm{~A}$. Current sharing result with power balance control technique 


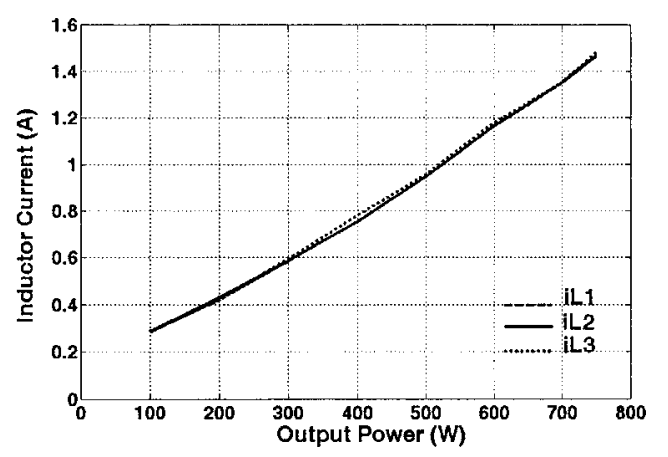

Fig. 21. Measured current in each module versus load variation (Digital power meter model $2531 \mathrm{~A}$ )

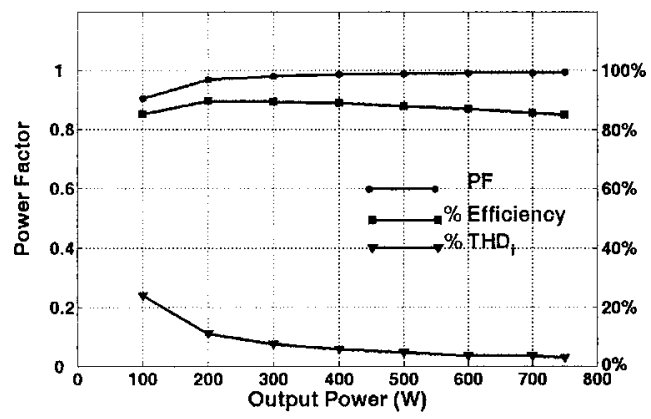

Fig. 22. Key performance characteristics of the $220 V_{r m s}$ single-phase modular converter system

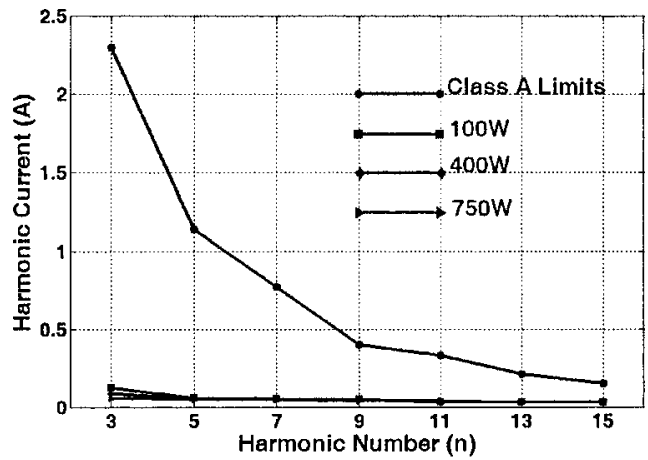

Fig. 23. Measured input current harmonics for the proposed rectifier at $V_{S}=220 V_{r m s}$

is shown in Fig. 21. It shows the effects of difference inductance values and parasitic in input inductor on current sharing. Practically, the inductance value is difficult to control. The inductor currents among each module are very slightly difference from light load to heavy load. Fig. 22 shows the key performance of the single-phase modular system at different power outputs. The upper curve in Fig. 22 presents the measured power factor for different output power. For the full load condition the power factor obtained is above 0.99 . The middle curve presents the efficiency of the system, it is approximately $85 \%$.

The lower curve presents the measured total harmonic distortion of the line current for different output power. It is observed that the THD of the line current is consistently below $3 \%$ for a line voltage $220 V_{r m s}$. Fig. 23 shows the current harmonics of the parallel CUK PFC circuit versus load variations. It shows the magnitude of the measured input current harmonics for the modular system operating under different power levels. It can be seen that over the rated power levels,

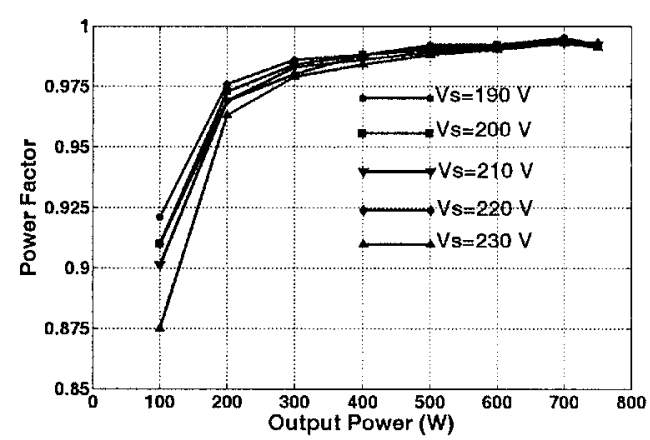

Fig. 24. Converter power factor versus output power for different input voltage values

this modular system conforms to the IEC-61000-3-2 class A limits. The only significant harmonics is the third which is about $3 \%$ of the class A limits. Thus, the output power of this modular converter may be expanded larger than $750 \mathrm{~W}$ with three-phase three or four wire system.

Fig. 24 shows the power factor for different load and input voltage conditions. As expected, increasing the input voltage worsens the power factor, especially at low output power. However, in the nominal condition, it is close to unity. The CUK PFC parallel scheme can provide good power factor from $200 \mathrm{~W}$ to full load. Both the power factor and $\mathrm{THD}_{i}$ are insensitive to the line voltage. Therefore, the CUK converters in CCM operation are suitable as power-factor-correction over a variation of input voltage.

\section{Conclusions}

A parallel-connected single-phase power factor correction topology using three non-isolated CUK converters is analyzed in this paper. Experimental prototype with a total of $750 \mathrm{~W}$ output power for three power modules and common output-48 V@-15.625 A has been built to verify the concept presented. The experimental results demonstrate that the proposed system works well. It has been shown that good output voltage regulation, input power factor correction and the inductor current sharing are achieved by controlling the duty-ratio for all modules. The proposed approach offers the following advantages: simple control and fast dynamic response. A high power factor $(\mathrm{PF}>0.99)$ can still be achieved. A $750 \mathrm{~W}$ prototype modular converter system with $85 \%$ efficiency operating completely in the CCM has confirmed the analysis.

Further research will be carried out on the three-phase source splitting configuration of the CUK PFC converters.

\section{Acknowledgment}

The authors are grateful to the Department of Electrical Engineering, Rajamangala University of Technology Lanna, Chiang Mai and King Mongkut's Institute of Technology North Bangkok (KMITNB), Bangkok, Thailand for the financial support of this project.

(Manuscript received April 14, 2005, revised Nov. 8, 2005)

\section{References}

( 1 ) J. Sebastian, M. Jaureguizar, and J. Uceda: "An overview of power factor correction in single-phase off-line power supply system", IECON 4., 20th, Vol.3, pp.1688-1693 (1994) 
( 2 ) D.S.L. Simonetti, J. Sebastian, and J. Uceda: "The discontinuous conduction mode Sepic and Cuk power factor preregulators: analysis and design", IEEE Trans. on Industrial Electron., Vol.44, No.5, pp.630-637 (1997)

( 3 ) S. Buso, G. Spiazzi, and D. Tagliavia: "Simplified control technique for high-power-factor flyback Cuk anf Sepic rectifiers operating in CCM", IEEE Trans. on Industrial Electron., Vol.36, No.5, pp.1413-1418 (2000)

( 4 ) L. Rossetto, G. Spiazzi, and P. Tenti: "Control technique for power factor correction converters", EPE 5., 6th, Italy (1994)

( 5 ) W.A. Tabisz, M.M. Jovanovic, and F.C. Lee: "Present and future of distributed power systems", APEC92., 7th, pp.11-18 (1992)

( 6 ) F.C. Lee, P. Barbosa, P. Xu, J. Zhang, B. Yang, and F. Canales: "Topoligies and design considerations for distributed power system applications", Proc. of IEEE, Vol.89, No.6, pp.939-950 (2001)

( 7 ) L.R. Lewis, B.H. Cho, F.C. Lee, and B.A. Carpenter: "Modeling, analysis and design of distributed power systems", PESC89., 20th, Vol.1, pp.152-159 (1989)

( 8 ) S. Kim and P.N. Enjeti: "A modular single-phase power-factor-correction scheme with a harmonic filtering function", IEEE Trans. on Industrial Electron., Vol.50, No.2, pp.328-335 (2003)

( 9 ) A. Newton, T.C. Green, and D. Andrew: "AC/DC power factor correction using interleaved boost and Cuk converters", IEE Conf. Publ., No.475, 8th, pp.293-298 (2000)

(10) S. Kim and P.N. Enjeti: "Control of multiple single-phase PFC modules with a single low-cost DSP”, IEEE Trans. on Ind. Appl., Vol.39, No.5, pp.13791385 (2003)

(11) Y.T. Feng, G.L. Tsai, and Y.Y. Tzou: "Digital control of a single-stage singleswitch flyback PFC AC/DC converter with fast dynamic response", PESC 01, 32nd, Vol.2, pp.1251-1256 (2001)

(12) R. Ayyanar, N. Mohan, and J. Sun: "Single-Stage Three-Phase Power-FactorCorrection Circuit using Three Isolated Single-Phase SEPIC Converters Operating in CCM", PESC 00, 31st, Vol.1, pp.353-358 (2000)
Uthen Kamnarn (Non-member) was born in Uttaratrid, Thailand, on

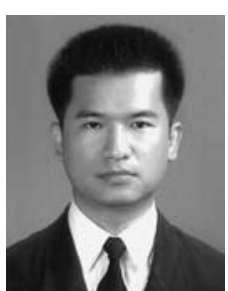
March 20, 1974. He received the BS degree in Electrical Engineering from the Ragamangala Institute of Technology (RIT), Patumtanee and Master degree in Electrical Engineering from KMITNB, Bangkok, Thailand in 2000 and 2003, respectively. He is currently a Ph.D. student at KMITNB. His main fields of research are Power Electronic Circuits, harmonics on power systems.

Viboon Chunkag (Non-member) was born in Nonthaburi, Thailand, on February 3, 1957. He received the Bachelor degree (Honors), Bs. Tech. Ed., from KMITNB and Master degree in Electrical Engineering from Kasetsart University, Bangkok, Thailand in 1979 and 1985, respectively. He received the Ph.D. degree in Electrical Engineering (Power Electronics) from University of BATH, United Kingdom in 1995. His main fields of research are Power Electronic Circuits, harmonics, active power filter and EMC\&EMI. 